\title{
Piratería, Plagio y ACCESO A la CULTURA
}

\author{
RAFAel J. PÉRez Miranda - UAM AzCAPOTZalco
}

\section{MÉXICO, OCTUBRE DE 2014}

\begin{abstract}
“Cuando tú me llamaste estaba viendo una película en copia pirata, en Europa todos somos pirata... La película está basada en la novela de Patricia Highsmith Two Faces of January; empecé a verla antes de que tú llamaras, y estoy viendo mi copia pirata. ${ }^{1}$
\end{abstract}

\section{Derechos de Autor, Plagio, Piratería}

La violación de los derechos de autor tiene en el debate jurídico diversas denominaciones, en general peyorativas; en los últimos tiempos la más popular es piratería, delito claramente tipificado en el derecho internacional y en los derechos positivos de la mayoría de los países; se intenta vincular en la mentalidad de la sociedad la simple copia no autorizada o la explotación de un producto por una persona no autorizada, con uno de los delitos más repudiado y que mereció ser tipificado en un tratado internacional. También se lo suele denominar plagio, por vinculación analógica con el delito cometido por una persona que vendía un hombre libre como si fuera esclavo, o en la actualidad con el secuestro extorsivo; los antecedentes del delito de plagio es ubicado por los autores en la antigua Roma, en la antigua Grecia e inclusive en el Deuteronomio. ${ }^{2}$ Ninguno de estos términos es adoptado en los derechos positivos nacionales, su uso se limita en parte a cierta doctrina, a la propaganda de cabilderos

\footnotetext{
'Žižek, Slavoj. En entrevista publicada en "El Universal”, México, 11 de octubre de 2014.

2/ MAUREL-INDERT, Hélène. Sobre el Plagio. Ed. Fondo de Cultura Económica. Buenos Aires, 2014, pág. 21. AGÚNDEZ FÉRNANDEZ, Antonio. Estudio jurídico del plagio literario. Ed. Biblioteca Comares de Ciencia Jurídica. Granada, 2005, págs.. 2 y ss.
} 
(también conocidos como lobistas) y a tratados internacionales a algunos de los cuales hacemos referencia infra. En razón de ello se suele recurrir, para brindar un concepto general, a definiciones de diccionarios acreditados que hacen referencia a la utilización de una obra por un tercero; no se hace referencia al hecho de si el autor "plagiado" es o no titular de un derecho de propiedad intelectual sobre la obra. ${ }^{3}$

Resulta contradictorio, en este marco, que se utilice la calificación de Pirata o Piratería en proyectos avanzados de importantes tratados internacionales, como el Acuerdo Estratégico Trans-Pacífico de Asociación Económica (Trans-Pacific Strategic Economic Partnership o Trans-Pacific Partnership)(TPP),y el Acuerdo Comercial Anti Falsificación(AntiCounterfeiting Trade Agreement) (ACTA), siendo que un convenio internacional con vocación universal tipifica de manera expresa el delito de piratería describiendo conductas totalmente diferentes:

Artículo 101. Definición de la piratería. Constituye piratería cualquiera de los actos siguientes: a) Todo acto ilegal de violencia o de detención o todo acto de depredación cometidos con un propósito personal por la tripulación o los pasajeros de un buque privado o de una aeronave privada y dirigidos: i) Contra un buque o una aeronave en la alta mar o contra personas o bienes a bordo de ellos; ii) Contra un buque o una aeronave, personas o bienes que se encuentren en un lugar no sometido a la jurisdicción de ningún Estado; b) Todo acto de participación voluntaria en la utilización de un buque o de una aeronave, cuando el que lo realice tenga conocimiento de hechos que den a dicho buque o aeronave el carácter de buque o aeronave pirata; c)

\footnotetext{
3/ AGÚNDEZ FERNANDEZ, ANTONIO. Estudio jurídico del plagio literario, op. cit., págs. 42 y ss.
} 
Todo acto que tenga por objeto incitar a los actos definidos en el apartado a) o en el apartado b) o facilitarlos intencionalmente. ${ }^{4}$

Ahora bien, cuando los autores hacen referencia a los primeros usos de estas analogías ponen como ejemplos casos ocurridos en épocas en las cuales no se había legislado sobre derechos de autor; así Maurel-Indart hace referencia a los orígenes griegos de la locución y Johns se remonta también a la antigua Roma, ambos destacan el inicio masivo de la violación de los derechos de autor a partir de la imprenta de Gutemberg; reconocen, sin embargo, la carencia de legislación protectora en estos períodos. Johns cita sus orígenes en el siglo XVII, fecha que coincide con el Estatuto de la Reina Ana; de ser así no contemplaría la piratería de las patentes a partir de la Parte Véneta o, en el caso inglés, del Estatuto de Jacobo I. ${ }^{5}$ A los efectos de este ensayo interesa rescatar, en estos estudios, la utilización ambigua de los términos al hablar de "piratería" o "plagio"

El uso de conceptos análogos, que sustituyen el que se puede considerar jurídicamente correcto, ha llevado además a unificar conductas diversas que merecen diferente trato legal o, en muchos casos, sólo moral.

Veamos algunas de las conductas a que se hace referencia:

a) Historias, leyendas, ideas generales, que son utilizadas por un artista, las desarrolla e integra en una obra, sin hacer, o haciendo, referencia a su origen: Por ejemplo las múltiples versiones en drama literario o musical de Don Juan; algunas obras de Shakespeare, las Variaciones sobre un tema de Joseph Haydn, de Brahms,en música.

4/ Convención de las Naciones Unidas sobre el Derecho del Mar. Entró en vigor el 16 de noviembre de 1994.

5/ MAUREL-INDERT, Hélène. Sobre el Plagio, op. cit. págs. 21, 25 y ss. JOHNS, Adrian. Piratería. Las luchas por la propiedad intelectual de Gutenberg a Gates. Ed. Akal, España 2013, págs. 41 y ss. 
b) La copia textual odisimulada de una obra o partes de una obra que no está protegida por derechos de propiedad intelectual (un relato de Las mil y una noches) sin citarla y atribuyéndose el copista la autoría.

c) La copia textual de una obra protegida, reconociendo al autor o autores, pero comercializándola sin su autorización.En este rubro se incluyen las copias de CD musicales, DVD sobre películas o series de televisión o la copia de programas de cómputo.

Estos casos a su vez se pueden subdividir.

1. Quién copia una obra que no se encuentra protegida por derechos de autor para lograr fama, reconocimiento, comete una falta a los usos sociales académicos que merecerá el repudio de sus pares.

2. Si se trata de una Institución Académica y la copia es publicada citando la relación del autor con la institución, ésta se verá perjudicada y deberá sancionar públicamente al autor del engaño; en el mismo caso también se vería afectada la revista científica que publicó la obra copiada. ${ }^{6}$

3. Si el autor copia una obra no protegida, la presenta como suya y luego la utiliza para obtener retribuciones económicas de diverso tipo: regalías por derechos de autor, estímulos de una institución académica, etcno se violaría derechos de autor pero se incurriría en una conducta repudiada por sus pares y reprimibles por parte de quienes hubieran aportado la retribución.

4. Si los herederos patrimoniales y morales de un autor publican obras que él había decidido mantener anónimas o no reeditar, estarán violando la voluntad del autor y recibirán múltiples críticas, pero habrán actuado conforme a derecho.

6/ Fue el caso conocido de investigadores japoneses del Centro para el Desarrollo Biológico de Kobe que publicaron en Nature información falsa destacando resultados exitosos en una investigación sobre células madres. 
Muchas de estas conductas presentan zonas grises que dificultan distinguir las ilegales o no éticas del uso justo de obras ajenas, y son fuente de la mayoría de los litigios; las disposiciones legales y las normas administrativas que se pueden utilizar para resolver estos casos divergen en los derechos positivos nacionales y en las normas académicas de universidades e institutos de investigación y no en todos los casos se realizan las distinciones que consideramos necesarias, según se verá infra.

La demonización de la violación de los derechos de autor y, en especial, de los derechos conexos, ha generado una especial preocupación gubernamental de reprimir penalmente la violación directa o indirecta de los derechos de autor, a limitar los derechos de los "presuntos delincuentes" llegando a la violación del principio de presunción de inocencia. La represión penal y la no distinción entre los distintos tipos de obras, por una parte, y entre la protección de los autores respecto a los intereses crematísticos de las corporaciones provocan, entre otros daños a la cultura, la destrucción de los productos que se consideran vinculados al "plagio"; a este aspecto nos referimos especialmente en este ensayo.

\section{VIOLACIÓN DE LOS DERECHOS DE UN AUTOR}

Ahora bien, cuando hablamos de violación de derechos de autor lo hacemos de manera muy genérica, ya que en principio y según los tratados internacionales este derecho es un derecho privado que se otorga al autor y que, en tanto excepcional privilegio monopólico, se limita a la interpretación restrictiva de la ley:

Acuerdo ADPIC, Preámbulo: .... Reconociendo que los derechos de propiedad intelectual son derechos privados... Convenio de Berna. Artículo 9 Derecho de reproducción: 1. En general; 2. Posibles excepciones; 3.Grabaciones sonoras y visuales. 1) Los autores de obras literarias y artísticas protegidas por el presente 
Convenio gozarán del derecho exclusivo de autorizar la reproducción de sus obras por cualquier procedimiento y bajo cualquier forma. ${ }^{7}$

La extensión de estos derechos privados corresponden a las legislaciones nacionales, que generalmente no aportan mayores precisiones, así la legislación mexicana expresa que:

Artículo 24.- En virtud del derecho patrimonial, corresponde al autor el derecho de explotar de manera exclusiva sus obras, o de autorizar a otros su explotación, en cualquier forma, dentro de los límites que establece la presente Ley y sin menoscabo de la titularidad de los derechos morales a que se refiere el artículo 21 de la misma. ${ }^{8}$

La legislación argentina, por su parte, dispone:

ARTICULO $2^{\circ}$ - El derecho de propiedad de una obra científica, literaria o artística, comprende para su autor la facultad de disponer de ella, de publicarla, de ejecutarla, de representarla, y exponerla en público, de enajenarla, de traducirla, de adaptarla o de autorizar su traducción y de reproducirla en cualquier forma. ${ }^{9}$

La legislación española a su vez, expresa:

Artículo 17. Derecho exclusivo de explotación y sus modalidades. Corresponde al autor el ejercicio exclusivo de los derechos de explotación de su obra en cualquier forma y, en especial, los derechos de reproducción, distribución, comunicación pública

7/ Convenio de Berna para la Protección de las Obras Literarias y Artísticas. Última enmienda el 28 de septiembre de 1979.

8/ LEY FEDERAL DEL DERECHO DE AUTOR. Diario Oficial de la Federación del 24 de diciembre de 1996. Última reforma publicada DOF 14-07-2014

`/ LEY N 11.723 - Régimen de la propiedad intelectual. Boletín Oficial: 30 de Septiembre de 1933. 
y transformación, que no podrán ser realizadas sin su autorización, salvo en los casos previstos en la presente Ley. ${ }^{10}$

De estos derechos otorgados en tratados internacionales y en las legislaciones nacionales derivan, o deberían derivar, las infracciones administrativas y delictuales que son denominadas genéricamente como piratería o plagio. Sin embargo, la ambigüedad en la tipificación de la ley autoral motiva que en cierta, o en gran, medida la precisión de los derechos otorgados a los autores surja de las disposiciones que describen y reprimen su violación.

Con motivo de la tendencia a penalizar la violación de los derechos de autor como un delito grave, uno de los accesorios de estas sanciones suele ser la posibilidad de destruir los productos plagiados y los instrumentos utilizados para la realización del plagio; las corporaciones han mostrado especial preocupación por este tema, ya que el regreso de los bienes plagiados al mercado o la reutilización de los instrumentos necesarios para el plagio las afecta de manera directa. Dos de los más importantes tratados internacionales negociados y en negociación así lo prevén:

Expresa el Tratado Trans Pacífico, conocido como TPP:

Artículo QQ.H.4.Y10. Cada parte designará que en procedimientos judiciales: ...

a. Cuando menos en relación a bienes pirata que lesionen los derechos de autor y bienes de marca falsificados, cada Parte designará que, en procedimientos jurídicos civiles, a petición del titular del derecho, sus autoridades judiciales están facultadas

\footnotetext{
10/ Real Decreto Legislativo 1/1996, de 12 de abril, por el que se aprueba el texto refundido de la Ley de Propiedad Intelectual, regularizando, aclarando y armonizando las disposiciones legales vigentes sobre la materia.
} 
a ordenar que dichos bienes infractores sean [VN propone: sean retirados de los circuitos comerciales o] destruidos, excepto en circunstancias excepcionales, sin compensación de ningún tipo. ${ }^{11}$

Similar redacción encontramos en el Tratado Internacional Antifalsificación, conocido como ACTA:

Art. 25: Aseguramiento, Decomiso y Destrucción. ... 3. Con respecto a los delitos previstos en los párrafos 1, 2, 3 y 4 del Artículo 23 (Delitos) para los cuales una de las Partes provee procedimientos y sanciones penales, dicha Parte establecerá que sus autoridades competentes estén facultadas para ordenar el decomiso o la destrucción de todos las mercancías de marca de fábrica o de comercio falsificadas o mercancías pirata que lesionan el derecho de autor. ${ }^{12}$

\section{LA OBRA DERIVADA Y EL USO JUSTO}

La historia del arte registra muchos casos en los que se han utilizado o copiado obras, protegidas o no por derechos de autor, para la elaboración de nuevas obras, por distintas causas y con diversos objetivos; en esta presentación nos interesan las artes visuales.

El Museo del Louvre era y es visitado por jóvenes artistas que, como partede su formación y aprendizaje copian obras de clásicos reconocidos en la historia del arte. Algunas de esas copias, por la calidad de los copistas y la fama adquirida, tienen un precio elevado en el mercado del arte; los copistas no actuaron con vocación mercantil, pero el producto se incorporó o se podría

\footnotetext{
11/ Publicación de WikiLeaks del Acuerdo Secreto de la Asociación Trans-Pacífico (TPP). Capítulo de Propiedad Intelectual Avanzada Para Todas las 12 Naciones con Posiciones de Negociación (30 de agosto 2013 texto de negociación consolidado entre corchetes). Se recurre a esta versión por la cláusula de secrecía que impide conocer la situación actual del debate; informalmente ha trascendido que hubo ya modificaciones en las bases de discusión de este capítulo, pero no en este punto.

${ }^{12}$ Acuerdo Comercial Anti - Falsificación (ACTA), rechazado por el Parlamento de la Unión Europea, firmado por México pero no aprobado por el Senado.
} 
incorporar al mercado; el Museo del Louvre ha expuesto muchas de estas copias como obras de arte destacadas. ${ }^{13}$

En otros casos, artistas plásticos han utilizado conscientemente obras conocidas y les han realizado modificaciones que, según su opinión, les otorga un valor o significado especial. Podemos citar casos famosos como La Monalisa modificada por Marcel Duchamp

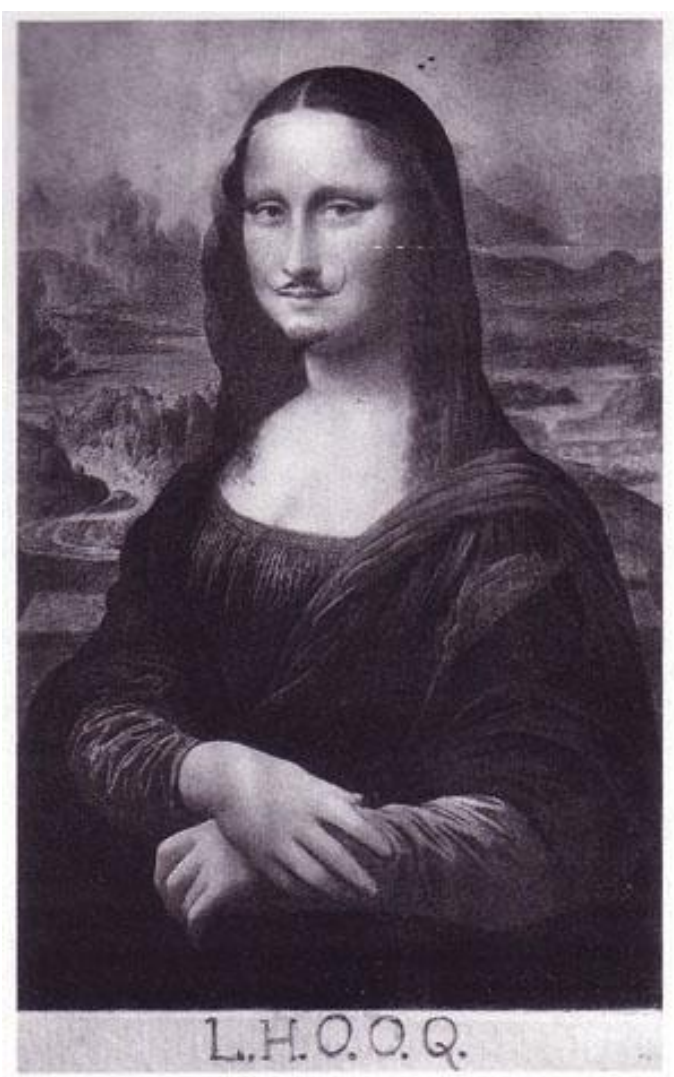

o la reproducción en pequeño de La victoria de Samotracia cubierta por Ives Klein con el color que lo caracteriza (protegido por un derecho de propiedad intelectual). ${ }^{14}$

13/ Exposición “Copiar, crear”, Museo del Louvre año 1993.

${ }^{14}$ / La Victoria de Samotracia de Ives Klein es parte del acervo del Museo Reina Sofía, Madrid, España 


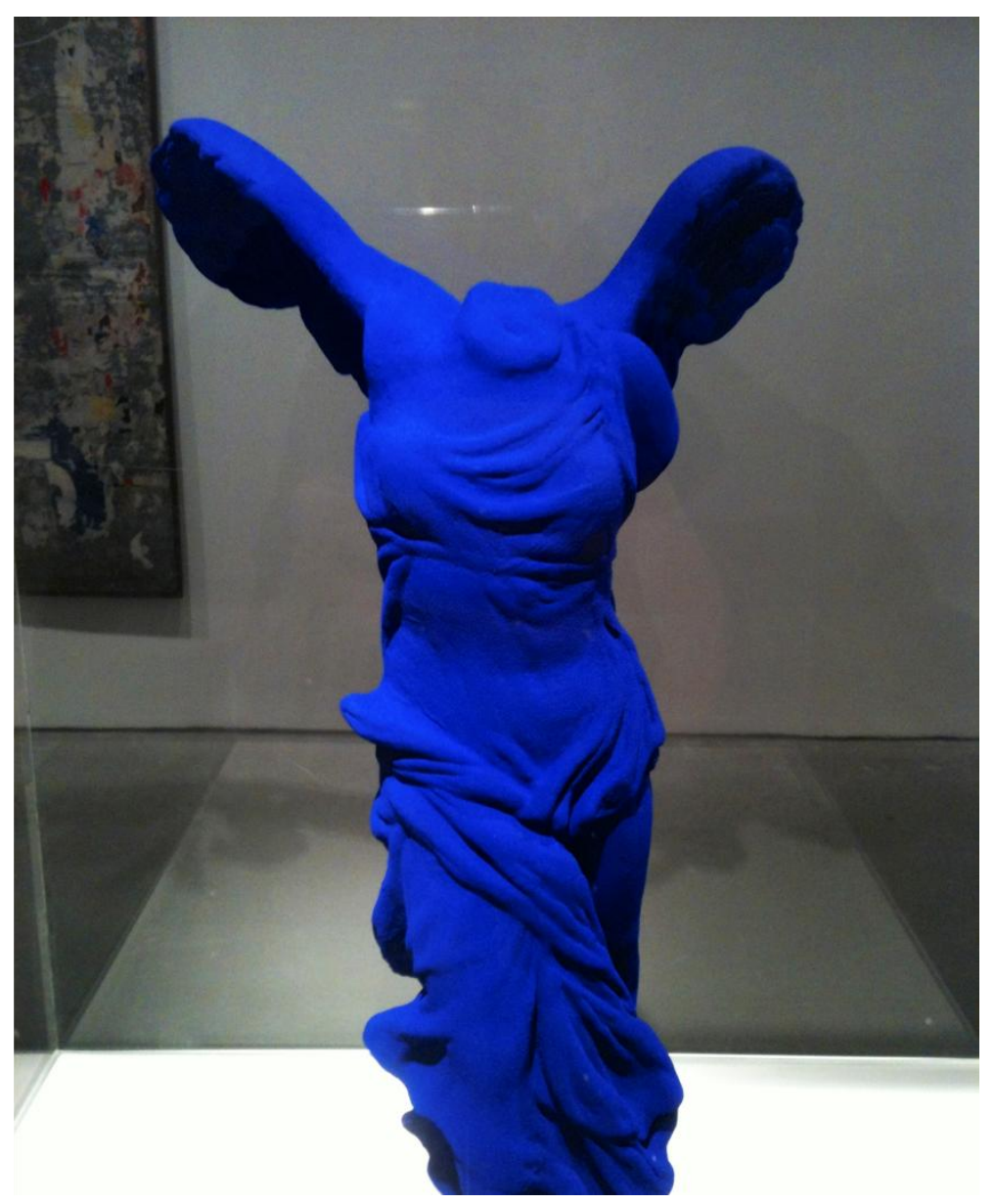

Merece atención especial la tendencia artística con presencia,en sus inicios, en Nueva York,a partir de la década de los 80 del siglo pasado, denominada Apropiacionista."Eran artistas que desde una actitud reflexiva y apropiativa habían abierto el arte a los media a partir de un proceso centrado en la crítica de la representación y en la concepción de imágenes a partir de otra". ${ }^{15}$ Estas obras pueden ser consideradas un plagio, una obra derivada o, según el sistema jurídico aplicable, un caso de uso justo.

Una obra derivada es, precisamente, la modificación de una obra preexistente que, por la especial importancia estética de la modificación, deriva en una nueva obra original. Según el derecho positivo nacional aplicable, el autor de la obra modificada deberá respetar los derechos

15/ GUASCH, Ana María. El arte último del siglo XX. Del posminimalismo a lo multicultural. Ed. Alianza Forma. Madrid, 2000, págs. 341 y ss. 
patrimoniales del autor de la obra base y, en su caso, susderechos morales. ${ }^{16}$ Ahora bien, estas modificaciones se refieren a traducciones, adaptaciones, compilaciones, anotaciones, etc., modificaciones en las cuales la "obra" sigue siendo la primigenia. ${ }^{17}$ A estas modificaciones se refiere la Convención de Berna:

Art. 2...3) Estarán protegidas como obras originales, sin perjuicio de los derechos del autor de la obra original, las traducciones, adaptaciones, arreglos musicales y demás transformaciones de una obra literaria o artística. ${ }^{18}$

Es diferente cuando el autor, el artista, toma ideas de una obra protegida, pero elabora una obra nueva que está claramente vinculada con ella pero también modificada de manera tal que se puede considerar una obra original y así es reconocida por los expertos, por los coleccionistas y por la mayoría del ambiente artístico. Muchos artistas, entre ellos los apropiacionistas, no consideran que han realizado una modificación, consideran que han realizado una obra de arte totalmente nueva, esencialmente diferente a la figura u objeto que les sirvió de base y que en consecuencia, su obra es totalmente original, por lo cual no es necesario hacer referencia a la obra origen ni reconocer derechos patrimoniales o morales a otro sujeto.

\section{EL USO JUSTO}

Estos artistas recurren en su argumentación jurídica a las excepciones a los derechos de autor conocidas como "uso justo", regulada en las legislaciones norteamericana y canadiense, con ciertas diferencias de contenido. Un respaldo sólido a su argumentación es el reconocimiento de la calidad estética original de las obras resultado de la "apropiación" por parte de sus pares, por los galeristas especializados y por los coleccionistas de arte

16/ Ver ROIG SERRANO, Miguel. Las Obras. En BUSCH, Cristina - Javier Gutiérrez Vicén - Miguel Roig - Mariona Sardá. El Futuro de la Creación Los derechos de autor de los creadores visuales. Ed. Fundación Arte y Derecho, Madrid 2003, págs. 67 y 68.

${ }^{17} /$ Ver también sobre las obras derivadas VILLALBA, Carlos - Delia Lipszyc. El Derecho de Autor en la Argentina. Ed. La Ley, Buenos Aires, 2001, pág 28.

18/ Convenio de Berna para la Protección de las Obras Literarias y Artísticas del 9 de septiembre de 1886. 
contemporáneo. Estamos en este caso en la distinción entre la originalidad subjetiva, que no se haya basado la obra en otra obra, o en la originalidad objetiva, una nueva obra que basada o no en una obra anterior tiene un valor especial, diferente, respecto la obra anterior. ${ }^{19}$

El "uso justo" es una institución reconocida, sujeta requisitos estrictos, en el derecho norteamericano y canadiense. En la interpretación del concepto de uso justo es conveniente destacar dos aspectos: a) la delgada línea que separa el uso justo del plagio y, b) las serias consecuencias que derivan de una u otra opción.

En efecto, para decidir sobre la existencia de "uso justo", en el derecho norteamericano, la justicia debe considerar cuatro puntos: a) El propósito y el carácter del uso, incluyendo si dicho uso es de naturaleza comercial o para fines educativos y no lucrativos b) La naturaleza de la obra protegida por los derechos de autor c) La cantidad y sustancialidad de la parte utilizada en relación con la obra en su conjunto d) El efecto del uso de la obra modificada sobre el mercado potencial o sobre el valor de la obra original protegida con derechos de autor ${ }^{20}$ Surge de esta conceptualización que en caso norteamericano el uso justo no está limitado, en principio, por la extensión de la reproducción, si no más bien por los perjuicios de todo tipo que se le puedan causar al autor; ahora bien el juez debe evaluar todos y cada uno de los ítems descritos. ${ }^{21}$

19/ BERCOVITZ RODRÍGUEZ CANO, Rodrigo. Manual de Propiedad Intelectual. $5^{\mathrm{a}}$. Ed. Ed. TIRANT LO BLANCH, Valencia, 2012, págs.. 48 y ss.

${ }^{20}$ / Ver sobre el tema, además, LIPSZYC, Delia. Nuevos temas de derecho de autor y derechos conexos. Ed. Zavalía, Buenos Aires 2004, cap. II, nota de pié de página 47. OWEN, Lynette. Comprar y vender derechos. Ed. Fondo de Cultura Económica, México, 2008.

21/ The Copyright Act of 1976. 107 . Limitationson exclusive rights: Fair use Notwithstandingtheprovisions of sections 106 and 106A, thefair use of a copyrightedwork, includingsuch use byreproduction in copies orphonorecordsorbyanyothermeansspecifiedbythatsection, forpurposessuch as criticism, comment, newsreporting, teaching (includingmultiple copies forclassroom use), scholarship, orresearch, isnotaninfringement of copyright. In determiningwhetherthe use made of a work in any particular case is a fair use thefactorsto be consideredshallinclude- (1) thepurpose and character of the use, includingwhethersuch use is of a commercialnatureorisfornonprofiteducationalpurposes; (2) thenature of thecopyrightedwork;(3) theamount and substantiality of theportionused in relationtothecopyrightedwork as a whole; and(4) theeffect of the use uponthepotentialmarketfororvalue of thecopyrightedwork. Thefactthat a workisunpublishedshallnotitself bar a finding of fair use ifsuchfindingismadeuponconsideration of alltheabovefactors. 
La legislación canadiense incluye también el concepto de uso justo (utilisationequitable), incluyendo requisitos similares a los estadounidenses si bien más estrictos: a) la finalidad de la utilización de la obra; b) la naturaleza de la utilización; c) el alcance de la utilización; d) alternativas de uso; e) la naturaleza de la obra; f) el efecto de la utilización de la obra; es decir, la extensión del uso es un elemento a considerar, si bien la ley no exige que se analice en cada caso la aplicación de todos los requisitos. ${ }^{22}$ La Unión Europea ha restringido en extremo los derechos emanados del principio de uso justo en el Capítulo II, en especial en el art. 5, de la Directiva 2001/29/EC, a la que debieron adecuar su legislación interna sobre derechos de autor los países miembros. ${ }^{23}$

\section{LA DESTRUCCIÓN DE LOS BIENES PLAGIADOS}

Nos interesa en este punto definir si en el caso en que se considerara que la obra modificada viola los derechos de autor debe recibir el mismo trato que cualesquier otro producto que se encuentre en la misma situación: un CD con reproducción de obras musicales, un DVD de una película o un libro, que se venden sin autorización de los titulares de derechos de propiedad intelectual; la decisión sobre si se han violado o no los derechos de autor es de difícil adopción, en especial cuando el demandado alega uso justo, pero también cuando alega modificación. Y el resultado de la decisión es más grave si si lleva aparejada la posible destrucción de la obra.

En efecto, la decisión de un tribunal puede afectar de manera directa la libertad de producción artística y por lo irreversible de la decisión, la historia del arte y el derecho humano de acceso a la cultura.

22/ GERVAIS, Daniel \& Elizabeth F. Judge. Le Droit de la PropriétéIntellectuelle. Ed. Thomson Carswell. Quebec, 2006, págs.. 83 y ss.

${ }^{23} /$ Directiva $N^{\circ}$ 2001/29/CEE del Parlamento de la Unión Europea, del 22 de mayo de 2001, relativa a la armonización de algunos aspectos del derecho de autor en la sociedad de la información. 
Sin embargo, la igualdad de trato a los casos ejemplificados pareciera surgir de las disposiciones de los Tratados Internacionales citados y de la legislación norteamericana sobre derechos de autor; ejemplificaremos la gravedad de la no distinción con un caso reciente.

\section{Un eJemplo esclarecedor, el Caso de Patrick Cariou vs Richard Prince}

Richard Prince, artista plástico reconocido, perteneciente a la corriente apropiacionista, se apropia, precisamente, de un gran número de fotografías del libro de Patrick Cariou Sí Rasta (PowerHouse Books, 2000), sin autorización del autor, sin citarlo y sin permiso del editor. Si bien en los lienzos resultantes estas fotografías son transformadas(se incorporan rayas, dibujos y pinturas), es fácil reconocer en ellas a las fotografías originales; este es un detalle menor ya que a posteriori Prince reconocerá que tomó, se apropió, de estas fotografías para sus obras.

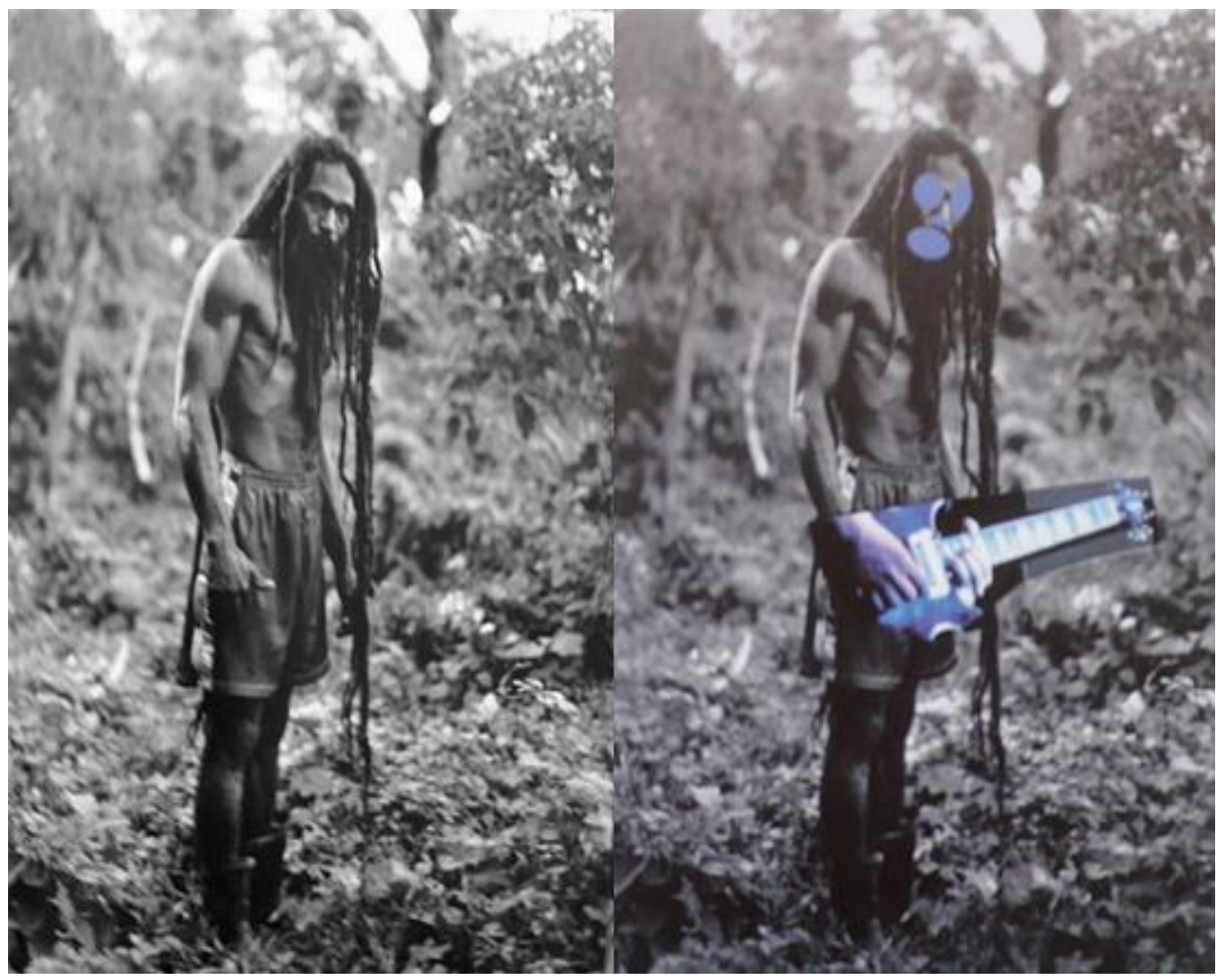


Cariou demandó a Prince y a la Galería de Arte que había organizado la exposición de sus obras y que lo representaba para la comercialización de ellas (Gagosian Gallery, Inc.). ${ }^{24}$

La demandada alegó "uso justo" conforme a la reforma de la ley norteamericana de derechos de autor de 1976, pero el Juez de Primera Instancia consideró que no cabía en la excepción y que se trataba de un plagio, que se habíanviolado los derechos de autor de Cariou. ${ }^{25}$

La sentencia de primera instancia, analiza ambas obras y no considera que se haya realizado una modificación sustancial que pudiera justificar la aplicación de las disposiciones sobre "uso justo". En razón de ello condena a los demandados y les ordena entregar todas las pinturas originales, las copias del libro editado con motivo de la exposición (Zona del Canal), todos los soportes materiales de la obra o de sus reproducciones consideradas infractoras de las fotografías originales (transparencias, placas, cintas, negativos de películas, discos); ordena además a los demandados que informen a quienes hayan comprado las obras que éstas violan los derechos de autor de Cariou y que por tanto no se pueden comercializar ni exhibir. El aspecto más importante es que originales y copias se deben entregar al actor quién determinará sobre su posible destrucción u otro destino.

"That Defendants shall within ten days of the date of this Order deliver up for impounding, destruction, or other disposition, as Plaintiff determines,..."26

La resolución del juicio de apelación resultó beneficioso para Prince; el Tribunal consideró que sus obras presentaban una estética totalmente diferente a las obras, fotografías, de

\footnotetext{
${ }^{24}$ / Patrick CARIOU, Plaintiff v. Richard PRINCE, Gagosian Gallery, Inc., Lawrence Gagosian, and Rizzoli International Publications, Inc. United States District Court, S.D. New York. No. 08 Civ. $11327(\mathrm{DAB})$.

${ }^{25}$ / Ver supra el capítulo Uso Justo

${ }^{26} /$ ibidem
} 
Cariou, al menos la mayoría de ellas, dejando por resolver cinco pinturas, las que remitió a la primera instancia para que realizara una apreciación sobre las mismas. ${ }^{27}$ Consideró en la sentencia que Prince era un reconocido artista de la corriente de los "apropiacionista", que reconocía como antecedentes obras como “Andy Warhol's Gold Marilyn Monroe”, serigrafía icónica sobre oro de una foto de Marilyn Monroe

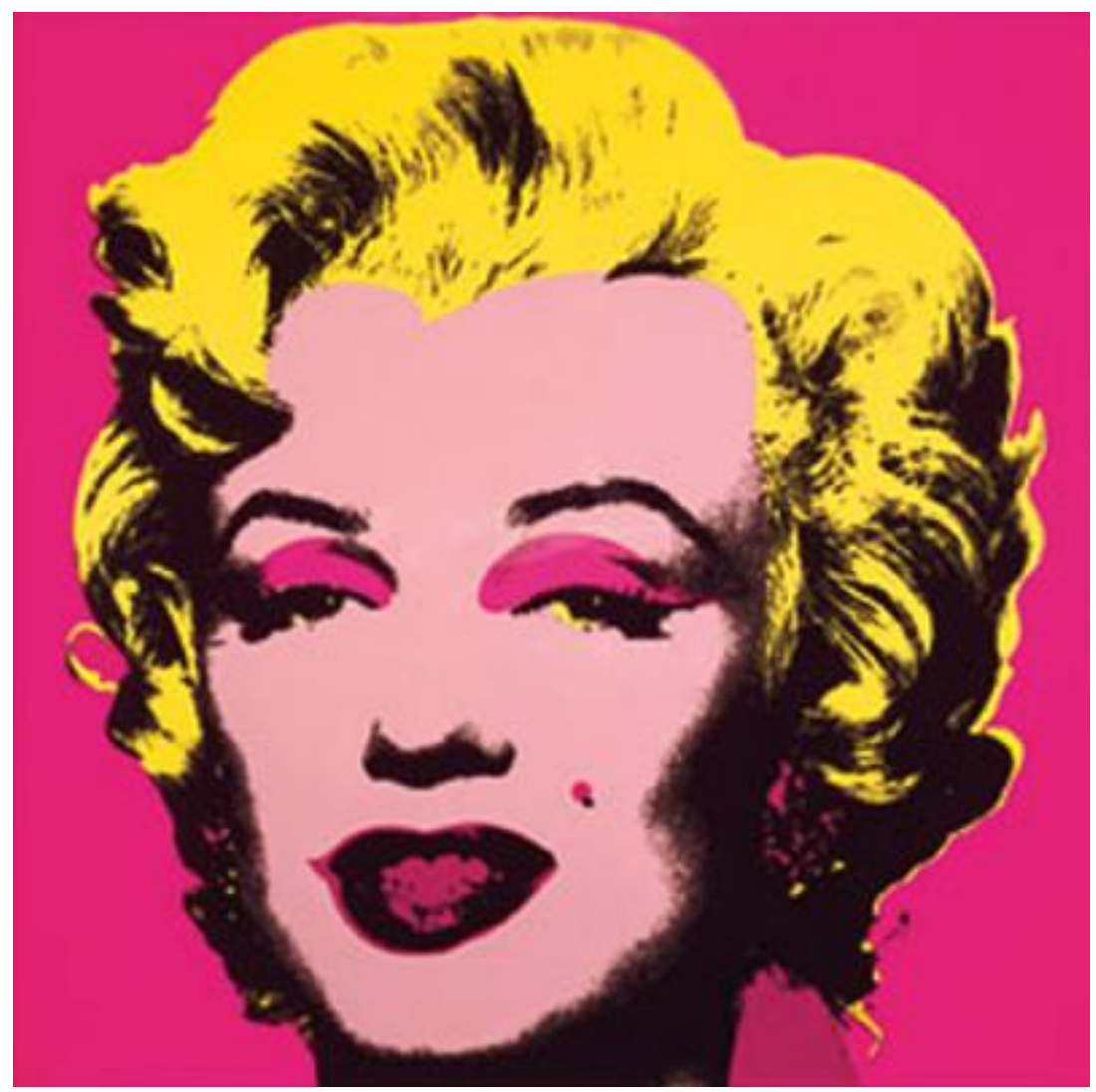

la obra de Robert Rauschenberg, Retroactiva I, que es una fotografía muy popular de John F. Kennedy serigrafiada al lado de una imagen de un astronauta en paracaídas, y muchas otras obras.

${ }^{27}$ / United States Court of Appeals.for the Second Circuit PATRICK CARIOU, V. RICHARD PRINCE, Plaintiff-Appellee,Defendant-Appellant, GAGOSIAN GALLERY, INC., LAWRENCE GAGOSIAN, Defendants-Appellants. ON APPEAL FROM THE UNITED STATES DISTRICT COURT FOR THE SOUTHERN DISTRICT OF NEW YORK 


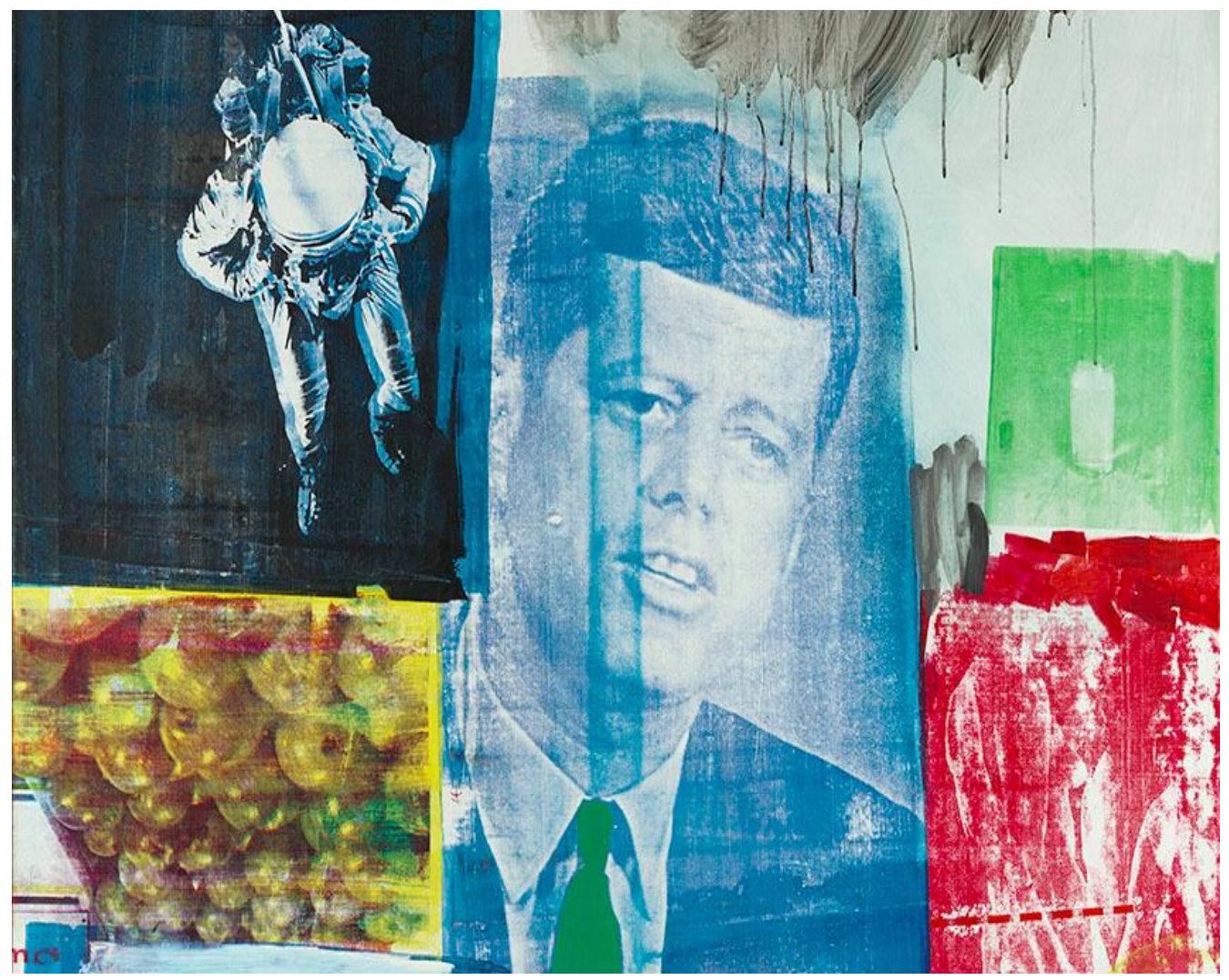

Luego de un análisis razonado de las corrientes artísticas contemporáneas relacionadas con los "apropiacionistas" y de la obra de Richard Prince, la Corte decidió que sus obras se adecuaban al concepto de "uso justo". Es interesante transcribir partes del resumen oficial de la sentencia pues el tribunal utiliza enfoques propios de la teoría del arte para decidir acerca de la transformación y modificación que otorgan originalidad a la obra de Prince:

'Similarly, here, no oneinterested in purchasingCariou'sbook of photographswouldviewPrince'swork as a substituteforCariou'swork. Theworks are completelydifferent. Cariou'sbook of photographssoughttocreate a book of "extreme classicalphotography, of portraiture." In contrast, Prince illustrates in a postapocalypticworld a fantasticalaccount of survivors of a nuclear holocaustwhocreatetheirownsocietywheremusicisthesurviving, ifnotredeeming, fact of life. Becauseit has no negativeimpactonCariou'smarket, and 
mayactuallyincreasethevalueforCariou'sworkbybringingattentiontoit,

Prince'sworkdoesnot in anywaydiminishCariou's incentive tocreatehiswork. Blanch, 467 F.3d at 250. Prince'sworks are as differentfromCariou's as Koons'swasfromBlanch's. Both Prince and Koons caricature thatwhichCariou and Blanch represent in a straightforwardmanner."

Si bien apartó de cinco de las obras para una reevaluación en primera instancia, decidió también que no se había causado ningún daño irreparable a Cariou y que no había ningún motivo para considerar que los daños sufridos, en su caso, no se pudieran salvar con el pago de una indemnización adecuada. Consideró además, sin mayor argumentación que la cita de precedentes, que no correspondía la destrucción de las obras

CONCLUSION. For the reasons discussed, we hold that all except five (Graduation, Meditation, CanalZone (2007), Canal Zone (2008), and Charlie Company) of Prince's artworks make fair use of Cariou's photographs. We express no view as to whether the five are also entitled to a fair use defense. We REMAND with respect to those five so that the district court, applying the proper standard, can determine in the first instance whether any of them infringes on Cariou's copyrights or whether Prince is entitled to a fair use defense with regard to those artworks as well. The judgment of the district court is REVERSED in part and VACATED in part. The case is REMANDED for further proceedings consistent with this opinion ${ }^{28}$

Es interesante la opinión disidente de WALLACE, J., Senior Circuit Judge, quién, reconociendo sus limitaciones para apreciar en profundidad las obras de artes que se presentaban como

28/Ibidem 
originales y plagiadas, aprueba en general la decisión pero cuestiona que el tribunal se considere competente para decidir sobre la mayoría de las obras y no sobre las cinco que se devuelven a primera instancia; considera que se deberían haber devuelto la totalidad para una evaluación más rigurosa..

Con posterioridad al fallo de la alzada, las partes en el conflicto arrivaron a un acuerdo privado cuyos términos no se conocen, lo cual impidió conocer la opinión de la Suprema Corte Justicia de Estados Unidossobre la interpretación de las disposiciones sobre uso justo y sobre los criterios o requisitos que debe considerar la justicia antes de ordenar la destrucción de una obra de arte, o posible obra de arte; queda sin embargo un espacio relevante a considerar por la doctrina y los legisladores de otros países, resultado de la política legislativa norteamericana y la argumentación jurídica que respalda la interpretación judicial respecto a los límites de los derechos de autor y de las decisiones sobre la posible destrucción de los posibles productos que materializan su violación. Es también una advertencia para quienes negocian tratados internacionales sobre propiedad intelectual y/o tratados internacionales con capítulos sobre propiedad intelectual, respecto a la consideración del vínculo entre esta y los derechos humanos de acceso a la educación y la cultura,en este caso.

\section{Algunas CONCLUSIONES}

Analizamos el caso Prince por la importancia que reviste la no distinción entre las diversas obras estéticas que pueden ser plagiadas y los resultados de las presiones de las grandes corporaciones para proteger sus intereses. En este caso nos encontramos con una sentencia de primera instancia y una resolución de la alzada totalmente diferentes, apreciaciones sobre la estética sustancialmente diversas, preocupación en el tribunal de apelación de fundar su fallo en un análisis histórico teórico de las corrientes contemporáneas en las artes plásticas e inclusive, 
la sincera opinión de uno de los miembros del Tribunal que manifiesta su incapacidad para opinar fundadamente sobre el meollo de la cuestión.

Pero ladiferencia de apreciación por parte de los jueces pudo derivar en la destrucción de importantes obras de arte, provocando un daño irreparable al artista, a los miembros de la sociedad que admiran al artista y pretenden disfrutar de sus obras, a los coleccionistas que tuvieran obra del autor, a los museosy galerías de arte que adquirieron y exhibeno comercializan estas obras.

Destruir copias de discos o videos que violan los derechos de autor, pero cuyos originales se encuentran resguardados, las denominadas copias piratas, es una sanción impulsada por las corporaciones que la consideran apropiadas para evitar daños a sus ingresos y al ingreso de los autores.

Pero la destrucción de obras de arte originales y de todas las reproducciones de las mismas en fotografías o videos, por la interpretación de jueces no necesariamente vinculados al mundo del arte, guardan precedentes que no recibieron una crítica favorable de la historia, como los decretos de la Santa Inquisición o las quemas de libros en la Alemania de Hitler. 


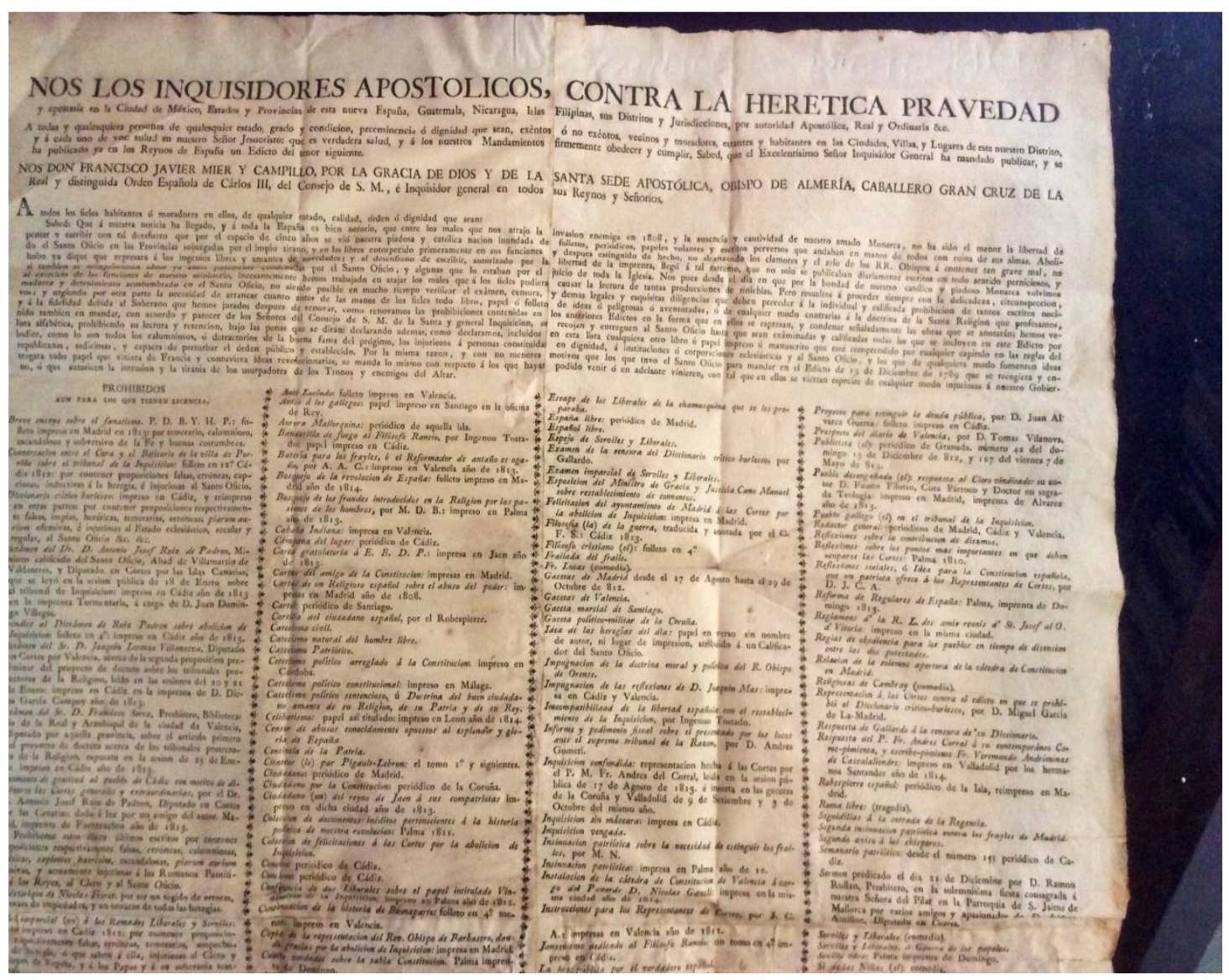

Es decir:

1. Una misma norma no se puede aplicar a cualquier tipo de soporte material de la creación artística; los originales de una pintura, de una escultura, de una instalación, guardan diferencias esenciales con los $\mathrm{CD}$ con música o programas de cómputo, o un DVD que es soporte material de una película.

2. Ordenar la destrucción de una obra plástica original, genera un daño irreparable a la cultura y viola los derechos humanos de libre expresión estética y los derechos humanos de acceso a la educación y a la cultura.

3. Se deben eliminar las sanciones penales y correccionales que penan la violación de los derechos de autor y de propiedad intelectual; los casos 
graves que afectan el interés público se encuentran sancionados en otros tipos penales específicos como fraude.

4. Se debe diseñar un cuerpo jurídico que estimule la creatividad intelectual totalmente diferenciado del sistema que protege a los derechos conexos y a las corporaciones que los explotan.

5. Las decisiones administrativas y judiciales que se refieran a una obra artística se debe sustentar en la opinión de los artistas, de sus pares, no en la simple opinión de los jueces, con o sin apoyo de peritos.

6. Las disposiciones más antiguas justifican el otorgamiento de derechos monopólicos a autores e inventores en el progreso de las artes y de la ciencia. Es necesario en consecuencia que las instituciones gubernamentales que además de la función de registro tienen facultades regulatarias y de interpretación, y en razón de ello de incidencia en las políticas públicas sobre la materia,cuenten con consejos con capacidad de decisión integrados por artístistas, críticos de arte, representantes de instituciones académicas y científicos de nivel reconocido y representantes de las academias de ciencia; estos consejos deben tener capacidad de decisión.

\section{BIBLIOGRAFÍA}

AGÚNDEZ FÉRNANDEZ, Antonio. Estudio jurídico del plagio literario. Ed. Biblioteca Comares de Ciencia Jurídica. Granada, 2005.

BERCOVITZ RODRÍGUEZ CANO, Rodrigo. Manual de Propiedad Intelectual. 5ª Ed. Ed. TIRANT LO BLANCH, Valencia, 2012.

BUSCH, Cristina - Javier Gutiérrez Vicén - Miguel Roig - Mariona Sardá. El Futuro de la Creación Los derechos de autor de los creadores visuales. Ed. Fundación Arte y Derecho, Madrid 2003.

GERVAIS, Daniel \& Elizabeth F. Judge. Le Droit de la PropriétéIntellectuelle. Ed. Thomson - Carswell. Quebec, 2006. 
GUASCH, Ana María. El arte último del siglo XX. Del posminimalismo a lo multicultural. Ed. Alianza Forma. Madrid, 2000.

JOHNS, Adrian. Piratería. Las luchas por la propiedad intelectual de Gutenberg a Gates. Ed. Akal, España 2013, págs. 41 y ss.

LIPSZYC, Delia. Nuevos temas de derecho de autor y derechos conexos. Ed. Zavalía, Buenos Aires 2004.

MAUREL-INDERT, Hélène. Sobre el Plagio. Ed. Fondo de Cultura Económica. Buenos Aires, 2014.

OWEN, Lynette. Comprar y vender derechos. Ed. Fondo de Cultura Económica, México, 2008.

ROIG SERRANO, Miguel. Las Obras. En BUSCH, Cristina - Javier Gutiérrez Vicén - Miguel Roig -

Mariona Sardá. El Futuro de la Creación Los derechos de autor de los creadores visuales. Ed. Fundación Arte y Derecho, Madrid 2003.

VILLALBA, Carlos - Delia Lipszyc. El Derecho de Autor en la Argentina. Ed. La Ley, Buenos Aires, 2001.

ŽIžEK, Slavoj. Entrevista publicada en periódico “El Universal”, México, 11 de octubre de 2014.

\section{DISPOSICIONES LEGALES Y FALLOS JUDICIALES}

Acuerdo Comercial Anti - Falsificación (ACTA), rechazado por el Parlamento de la Unión Europea, firmado por México pero no aprobado por el Senado.

Convención de las Naciones Unidas sobre el Derecho del Mar. Entró en vigor el 16 de noviembre de 1994.

Convenio de Berna para la Protección de las Obras Literarias y Artísticasdel 9 de septiembre de 1886. Última enmienda el 28 de septiembre de 1979.

Directiva $N^{\circ}$ 2001/29/CEE del Parlamento de la Unión Europea, del 22 de mayo de 2001, relativa a la armonización de algunos aspectos del derecho de autor en la sociedad de la información.

Exposición “Copiar, crear”, Museo del Louvre año 1993. 
LEY FEDERAL DEL DERECHO DE AUTOR. Diario Oficial de la Federación (México) del 24 de diciembre de 1996. Última reforma publicada DOF 14-07-2014

Patrick CARIOU, Plaintiff v. Richard PRINCE, Gagosian Gallery, Inc., Lawrence Gagosian, and Rizzoli International Publications, Inc. United States District Court, S.D. New York. No. 08 Civ. 11327(DAB).

The Copyright Act of 1976. 107 . Limitationson exclusive rights: Fair use Notwithstandingtheprovisions of $\underline{\text { sections } 106}$ and 106A, thefair use of a copyrightedwork, includingsuch use byreproduction in copies orphonorecordsorbyanyothermeansspecifiedbythatsection, forpurposessuch as criticism, comment, newsreporting, teaching (includingmultiple copies forclassroom use), scholarship, orresearch, isnotaninfringement of copyright. In determiningwhetherthe use made of a work in any particular case is a fair use thefactorsto be consideredshallinclude-(1) thepurpose and character of the use, includingwhethersuch use is of a commercialnatureorisfornonprofiteducationalpurposes; (2) thenature of thecopyrightedwork;(3) theamount and substantiality of theportionused in relationtothecopyrightedwork as a whole; and(4) theeffect of the use uponthepotentialmarketfororvalue of thecopyrightedwork. Thefactthat a workisunpublishedshallnotitself bar a finding of fair use ifsuchfindingismadeuponconsideration of alltheabovefactors.

United States Court of Appeals.for the Second Circuit PATRICK CARIOU, V. RICHARD PRINCE, Plaintiff-Appellee,Defendant-Appellant, GAGOSIAN GALLERY, INC., LAWRENCE GAGOSIAN, Defendants-Appellants. ON APPEAL FROM THE UNITED STATES DISTRICT COURT FOR THE SOUTHERN DISTRICT OF NEW YORK

WikiLeaks del Acuerdo Secreto de la Asociación Trans-Pacífico (TPP). Capítulo de Propiedad Intelectual Avanzada Para Todas las 12 Naciones con Posiciones de Negociación (30 de agosto 2013 texto de negociación consolidado entre corchetes). 